\title{
Erythroderma: a dermatologic emergency
}

\author{
Tony F. Bruno, MSc, MD; ${ }^{*}$ Parbeer Grewal, $\mathrm{MD}^{\dagger}$
}

\section{ABSTRACT}

Erythroderma is a potentially fatal dermatologic emergency that is often mistaken for infection. Indeed, the fact that it is difficult to diagnosis is the main contributor to its significant mortality rate, as treatment is readily available. We present a case of a 36-year-old man who was incorrectly diagnosed and treated for 2 months. We review the etiologies, initial work-up and management of this disease. In our case, the patient was ill, had lost $11.3 \mathrm{~kg}$ and developed systemic inflammatory response syndrome. Without proper treatment he was at risk of developing full-blown sepsis. Although there are many causes of erythroderma, prompt initial treatment directed at the underlying etiology typically results in a rapid remission.

\section{RÉSUMÉ}

L'érythrodermie constitue une urgence dermatologique potentiellement fatale qui peut souvent être confondue avec une infection. De fait, on attribue principalement l'important taux de mortalité associé à la maladie au fait qu'elle est difficile à diagnostiquer, alors qu'en soi, elle se traite facilement. Nous présentons ici le cas d'un homme de 36 ans qui a reçu un traitement inadéquat pendant deux mois pour un diagnostic erroné. Nous passons en revue les étiologies, les analyses et la prise en charge initiales de cette maladie. Dans ce cas-ci, le patient était mal en point, il avait perdu 11,3 kg et présentait un syndrome de réponse inflammatoire systémique. Faute de traitement approprié, il se trouvait exposé à un risque de sepsis avéré. Bien qu'il y ait de nombreuses causes de l'érythrodermie, un traitement initial instauré sans délai et selon l'étiologie sous-jacente procure généralement une rémission rapide.

$\overline{\text { Keywords: erythroderma, exfoliative dermatitis, red man }}$ syndrome

\section{INTRODUCTION}

Erythroderma, also known as the red man syndrome or as exfoliative dermatitis, is defined as a generalized redness and scaling of the skin. It is a clinical manifestation of a variety of underlying diseases, including malignancy

(e.g., cutaneous T-cell lymphoma and paraneoplastic phenomena), pre-existing dermatoses (e.g., atopic dermatitis, psoriasis, seborrheic dermatitis and pityriasis rubra pilaris), drug reactions, bullous disorders and allergic contact dermatitis. In up to $25 \%$ of cases, no underlying cause is found, and so it is termed idiopathic erythroderma. ${ }^{1}$

Erythroderma accounts for $1 \%$ of all dermatologic admissions to hospital and is more commonly seen in male patients. The importance of this disease is highlighted by the consequences of losing the cutaneous barrier: those affected are prone to lose heat, water, protein and electrolytes, and they are more susceptible to cutaneous infections. ${ }^{2}$ The disease can be mistaken as an infectious process and treated as such. The purpose of this case report is to highlight the pertinent clinical findings of erythroderma and its differentiation from infectious or malignant etiologies.

\section{CASE REPORT}

A 36-year-old man presented to our emergency department (ED). His chief complaint was a generalized pruritic rash ongoing for approximately 2 months. He also complained of concomitant fevers, night sweats and generalized malaise. Over the course of the previous 2 months he had seen his general practitioner and been to a walk-in clinic. Both times, he was given diphenhydramine hydrochloride and a topical corticosteroid without much relief. Ten days before his ED visit, he had also been treated with intravenous cefazolin for 2 days, and then switched to oral cloxacillin. He stopped taking the oral cloxacillin after 2 days as he felt it was not helping. He was prescribed oral prednisone, but only took a 4-day course, stopping it because it also appeared to be ineffective.

On the day of his presentation to our ED, in addition

From the Departments of *Family Medicine and †Dermatology, University of Alberta Hospital, Edmonton, Alta.

Submitted Aug. 9, 2008; Revised Dec. 4, 2008; Accepted Dec. 23, 2008

This article has been peer reviewed.

CJEM 2009;11(3):244-6

$2442009 ; 11(3)$

$C J E M \bullet J C M U$ 
to the pruritic rash, he continued to complain of fevers, profuse sweating and generalized skin desquamation. He denied any history of travel outside of Canada, exposure to farms, recent illness or history of skin disease in general. He worked as an underground diamond miner, and was exposed to a variety of chemicals and oils, although he denied exposure to any new chemicals at home or in the workplace. He was not taking any other medications. He also denied any significant medical or surgical history.

On physical examination, all vital signs were normal except for tachycardia at 130 beats/min. He was afebrile, although extremely warm to touch. Perspiration soaked through his clothes and bed linens multiple times while he was in the ED. His temperature was measured repeatedly, as his normothermic temperature appeared unlikely given such impressive exothermia. He looked unwell, but nontoxic. His examination was otherwise unremarkable except for the rash. It was

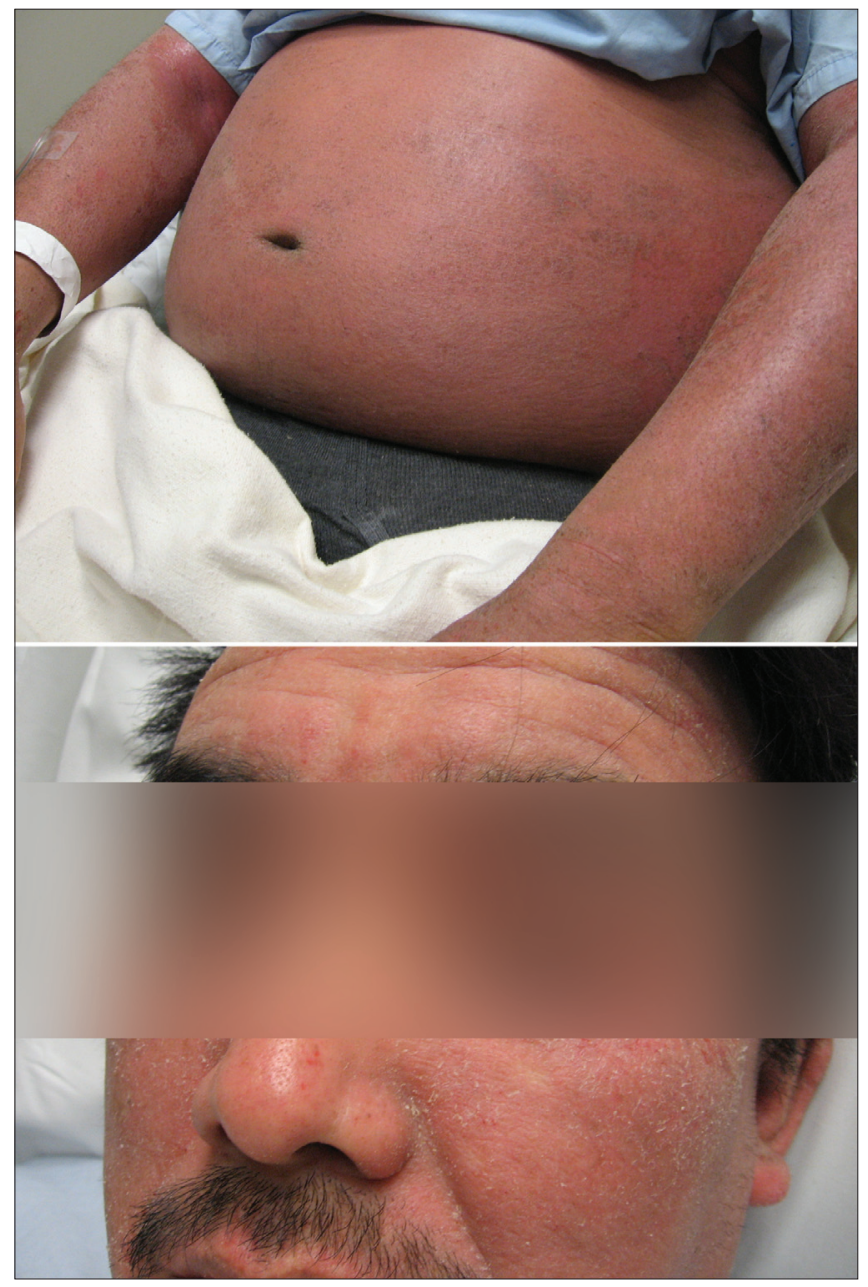

Fig. 1. Erythematous rash with desquamation diffusely on the patient's trunk, arms and face. a symmetric, generalized, total body, erythematous rash with prominent scaling and desquamation, most notably on his face and arms (Fig. 1). He also had shallow erosions bilaterally on both shins (Fig. 2). Notable abnormal laboratory investigations included a white blood count of $26.8 \times 10^{9} / \mathrm{L}$ and a normal neutrophil count. The particular eosinophilia was $12 \times$ $10^{9} / \mathrm{L}$. Lactate was $2.4 \mathrm{mmol} / \mathrm{L}$ and his albumin was $31 \mathrm{~g} / \mathrm{L}$ (total protein was $49 \mathrm{~g} / \mathrm{L}$ ). All other laboratory tests were normal. Skin swabs were taken of the erosions and a skin biopsy performed. The patient was admitted, started on intravenous vancomycin and clindamycin and topical betamethasone $0.1 \%$ cream. Swabs taken from the shallow erosions eventually grew mixed Staphylococcus and Streptococcus species and his biopsy showed subacute spongiotic dermatitis consistent with allergic contact dermatitis. He was therefore diagnosed with erythroderma secondary to allergic contact dermatitis and started on oral prednisone at a dose of $0.5 \mathrm{mg} / \mathrm{kg} /$ day.

\section{DISCUSSION}

Erythroderma typically presents with generalized erythema and scaling, classically affecting greater than $90 \%$ of the total body surface area. Other manifestations include diffuse alopecia, keratoderma, nail dystrophy, ectropion, peripheral edema and lymphadenopathy. ${ }^{3}$ Symptoms generally include fevers, malaise, fatigue and pruritus. Significant systemic complications include fluid and electrolyte abnormalities, hypoalbuminemia, thermoregulatory disturbance, cardiac failure, capillary leak syndrome, infection and possibly even death. ${ }^{4}$ There have been varied mortality rates from

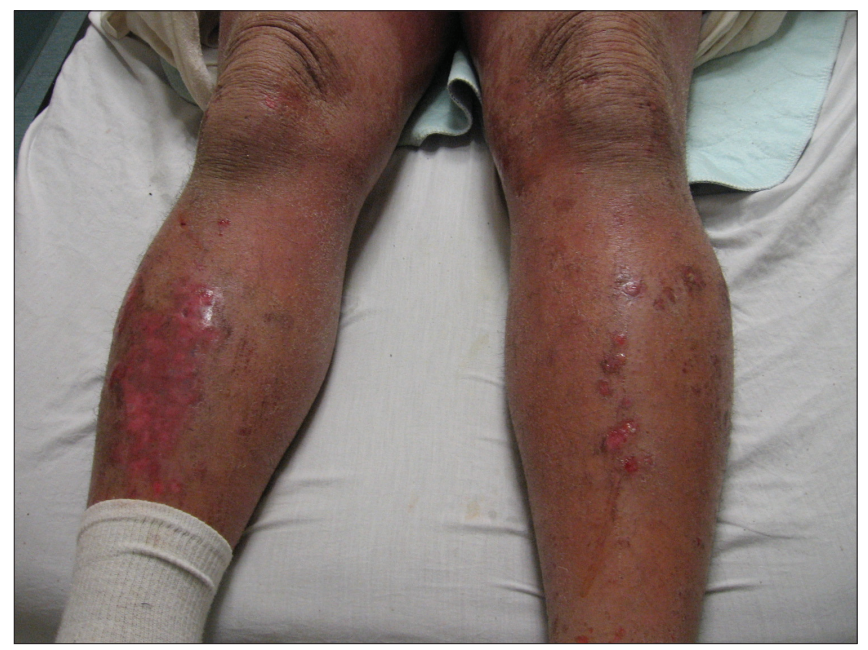

Fig. 2. Shallow erosions on both of the patient's shins. 
$18 \%$ to $64 \%$ published, though mortality has been reduced, generally because of advances in diagnosis and treatment. ${ }^{5}$

Because of the extensive rash, fever, fatigue and potential for lymphadenopathy and weight loss, the presentation of erythroderma can masquerade as, or be a manifestation of, more sinister conditions including lymphoma (Sézary syndrome). Indeed, erythroderma may be a presentation of reticuloendothelial or intravascular neoplasms, so it is incumbent on the physician to perform a thorough investigation. An algorithmic approach to the erythrodermic patient begins with a thorough history, including a complete drug history. The physical examination requires specific attention to the vital signs, nails, mucosa and lymph nodes and the possibility of hepatosplenomegaly. Baseline blood work and skin biopsies, along with a biopsy of enlarged lymph nodes, is usually the next step in the evaluation. Further investigations, such as chest radiography, patch testing and biopsies for immunofluorescence, can be carried out as needed. ${ }^{6}$

Determining the underlying etiology and removing any contributing external factors remain the most important factors in treating erythroderma. ${ }^{7}$ Erythroderma is considered a dermatologic emergency; patients should be admitted to hospital promptly for treatment. Almost any drug can induce erythroderma; therefore any potential offending agents should be stopped. Generalized treatment of this condition includes hydration to maintain a normal volume status, monitoring and correcting electrolyte abnormalities, keeping patients afebrile and instituting gentle skin care measures. For crusted sites one can use oatmeal baths or wet dressings followed by bland emollients and low potency topical corticosteroids. ${ }^{4}$ High potency topical corticosteroids are generally avoided because of the possibility of increased systemic absorption due to the compromised cutaneous barrier. ${ }^{8}$ Antihistamines can be used for the associated pruritus. If there are any signs of secondary infection, systemic antibiotics should be started. If a drug reaction is suspected, oral corticosteroids at an initial dose of $1-2 \mathrm{mg} / \mathrm{kg} /$ day may be initiated. ${ }^{1}$

\section{CONCLUSION}

Erythroderma is a complex disorder whose prognosis depends on the etiologic cause. Virtually all cases of drug-induced erythroderma recover completely with prompt initial management and removal of the offending drug. However, erythroderma can often be clinically mistaken for other presentations, such as an infection, leading to higher mortality rates especially in the very young and elderly. The attending emergency physician should always consider a broad differential diagnosis when assessing a patient with possible erythroderma. Individualized treatment based on the underlying etiologic cause should be combined with supportive skin care to ensure optimal outcomes.

Acknowledgement: The authors would like to thank the Departments of Family Medicine/Emergency Medicine and Dermatolgy for the funding contribution of this work.

Competing interests: None declared.

\section{REFERENCES}

1. Bolognia JL, Jorizzo JL, Rapini RP. Dermatology. 2nd ed. Toronto (ON): Mosby Elsevier; 2008. p. 149.

2. Karakayli G, Beckham G, Orengo I, et al. Exfoliative dermatitis. Am Fam Physician 1999;59:625-30.

3. Botella-Estrada R, Sanmartin O, Oliver V, et al. Erythroderma: a clinicopathological study of 56 cases. Arch Dermatol 1994;130:1503-7.

4. Rothe MJ, Bialy TL, Grant-Kels JM. Erythroderma. Dermatol Clin 2000;18:405-15.

5. Sehgal VN, Srivastava G, Sardana K. Erythroderma/exfoliative dermatitis: a synopsis. Int 7 Dermatol 2004;43:39-47.

6. Rothe MJ, Bernstein ML, Grant-Kels JM. Life-threatening erythroderma: diagnosing and treating the "red man". Clin Dermatol 2005;23:206-17.

7. Wilson DC, Jester JO, King LE Jr. Erythroderma and exfoliative dermatitis. Clin Dermatol 1993;11:67-72.

8. Aalto-Korte K, Turpeinen M. Quantifying systemic absorption of topical hydrocortisone in erythroderma. Br 7 Dermatol 1995;133:403-8.

Correspondence to: Dr. Tony F. Bruno, Department of Family Medicine, CCFP-EM Program, Faculty of Medicine and Dentistry, 205 College Plaza, University of Alberta, Edmonton AB T6G 2R3; tfbruno@shaw.ca 